\title{
Morphological alterations in the jejunal mucosa of aged rats and the possible protective role of green tea
}

\author{
Zeinab A. Hassan ${ }^{1,2}$, Agata Zauszkiewicz-Pawlak ${ }^{3}$, Shaimaa A. Abdelrahman, ${ }^{2}$ \\ Sami Algaidi', Maha Desouky ${ }^{1,4}$, Sally M. Shalaby ${ }^{5}$ \\ ${ }^{1}$ Department of Anatomy, Taibah Univeristy, Kingdom of Saudi Arabia \\ ${ }^{2}$ Departments of Histology and Cell Biology, Faculty of Medicine, Zagazig University, Zagazig, \\ Egypt \\ ${ }^{3}$ Department of Histology, Medical University of Gdansk, Gdansk, Poland \\ ${ }^{4}$ Department of Anatomy, Faculty of Medicine, Menia University, Egypt \\ ${ }^{5}$ Department of Medical Biochemistry, Faculty of Medicine, Zagazig University, Zagazig, Egypt
}

\begin{abstract}
Introduction. Gastrointestinal disorders become more prevalent with ageing. This study is aimed to describe morphological changes that occur in the jejunal mucosa of male albino rats as a result of ageing and the protective effect of green tea (GT) extract.

Material and methods. The experiment was performed on sixty rats: thirty young-adult (6-month old, body mass 200-220 g) and thirty old (24-month-old, body mass 220-260 g) animals. Each group was further divided into two subgroups $(\mathrm{n}=15 \mathrm{each})$ : control rats and GT-treated rats that received $1.5 \mathrm{~mL}$ ( $300 \mathrm{mg} / \mathrm{kg} / \mathrm{day})$ of GT extract for 14 weeks by oral gavage. Sections of the jejunum were stained with hematoxylin and eosin, periodic acid Schiff, toluidine blue and Mallory trichrome methods. The presence of proliferating cell nuclear antigen (PCNA)- and CD68-positive cells was evaluated by immunohistochemical staining. Ultrathin sections were prepared and examined by a transmission electron microscope (TEM).

Results. Jejunal sections of the old control rats showed distortion of submucosa and attenuated muscularis externa with decreased height of intestinal villi. The villi also showed partial loss of acidophilic brush border with wide spaces between enterocytes. Swollen, short, blunt or broad villi with abundant mononuclear cell infiltration of lamina propria and congested blood vessels were evident both by light and electron microscopy. The number of PCNA- and CD68-positive cells in jejunal mucosa of old rats was higher than in young rats. The activity of glutathione peroxidase (GPX) and total antioxidant capacity (TAC) in the mucosa of old control rats were lower, whereas malondialdehyde (MDA) levels were higher in the jejunal homogenates of old rats as compared to young control rats. Administration of GT extract protected the jejunal mucosa from age-related changes by restoring its histological structure. The treatment of old rats with GT extract significantly decreased MDA levels in the jejunum and increased TAC and GPX activity.

Conclusions. The age-related changes of the morphology of rat jejunum could be ameliorated by prolonged supplementation of the green tea extract. (Folia Histochemica et Cytobiologica 2017, Vol. 55, No. 3, 124-139)
\end{abstract}

Key words: rat; aging; jejunal mucosa; morphology; green tea; PCNA, CD68; IHC; TEM

Correspondence address: Prof. Z.A. Hassan

Department of Anatomy, Taibah University Madinah Moumauarah, Kingdom of Saudi Arabia e-mail: zeinabrehim66@gmail.com

\section{Introduction}

The gastrointestinal (GI) tract is comprised of structurally and functionally distinct regions. It holds the largest population of neurons and most complex system of nervous tissue outside the central nervous system as well as the greatest number of immune cells in the body and a variety of specialized epithelial cells [1]. 
The small intestine is the primary digestive apparatus of mammals. It absorbs nutrients via the intestinal epithelial cells, i.e. enterocytes. Villi and microvilli have a major role in increasing the intestinal surface area [2]. There is a rapid, almost complete renewal of the functional villus epithelium by the stem cells of the crypts of Lieberkuhn every 2 to 6 days [3]. Intestinal stem cells are pluripotential and give rise to all cell lineages in the intestinal epithelium. Mucosal cell proliferation is essential for the maintenance of the integrity of the GI system while the proliferation rates are high, second only to hematopoietic system [4].

Aging is a multifactorial process, which comprises both intrinsic and extrinsic factors, and age-related gastrointestinal dysfunction has a major impact on the quality of life. Disorders of the GI tract are prevalent amongst the elderly population [5, 6]. Aging of the cells of the GI tract is likely to be involved in the etiology of GI disorders. Also other factors, such as exercise, diet and the microbiota may influence both function and properties of GI cells during aging which affects body's ability to maintain homeostasis $[1,6,7]$. These deteriorations result in the increased prevalence of certain diseases associated with aging, such as gastroesophageal reflux, intestinal inflammation and constipation $[1,8]$.

The effects of aging on the human body vary depending on tissue, and it was shown that organ systems with higher cell turnover, including the GI epithelium, experienced the highest cumulative DNA damage [9]. Aging was shown to be associated with the accumulation of oxidative damage to DNA and other cellular components and tissues during lifetime [10]. Oxidative damage to DNA, proteins, carbohydrates and lipids are likely causes of degenerative diseases due to disturbances in cellular homeostasis [10]. Many markers were used to measure the oxidative stress-associated tissue damage and antioxidant defense including measurement of antioxidant enzyme activities [11].

Another aspect of aging-related impairment of the intestinal epithelium are inflammatory processes. Since the intestinal macrophages are the largest population of mononuclear phagocytes in the body, they are the vital part of the first-line defense mechanisms against the pathogenic microorganisms and their immunostimulatory products [12].

Green tea (GT) is a popular drink used worldwide by more than two-thirds of the world's population. It is obtained from leaves and the terminal apical buds of Camellia sinensis. GT leaves contain caffeine, theobromine, theophylline and phenolic acid. GT also contains methylxanthines and polyphenols, especially flavonoids of the catechin type. The four kinds of catechins mainly present in GT leaves are epicatechin, epigallocatechin, epicatechin-3-gallate and epigallocatechin-3-gallate (EGCG) [13]. The role of tea catechins in decreasing risk of many diseases and maintenance of a healthy physiological status have been thoroughly documented throughout different stages of life [14]. GT has well-established hypocholesterolemic, anti-hyperglycemic, hepatoprotective and anticarcinogenic effects [15]. Also, GT stimulates production of endogenous antioxidants during oxidative stress, ischemia and inflammation. It prevents apoptosis process by altering expression of the anti- and proapoptotic genes [16]. Long-term ingestion of tea decreases the age-related declines in physical performance and energy metabolism in senescence-accelerated mice [17]. Therefore, the aim of this study was to explore age-related changes in the jejunal mucosa of male Wistar albino rats and the possible protective role of GT administration.

\section{Material and methods}

Green tea extract. Green tea extract which consist of $70 \%$ total catechin, $4.39 \%$ epigallocatechin (EGC), $1.26 \%$ catechin (C), $43.95 \%$ epigallocatechin-3-gallate (EGCG), $2.9 \%$ epicatechin (EC) and $17.5 \%$ epicatechin-3-gallate (ECG) was purchased (El-Obour Modern Pharmaceutical Industries, Obour City, Egypt) in the form of tablets, each containing $200 \mathrm{mg}$ of the extract. Briefly, 100 tablets were dissolved in $100 \mathrm{~mL}$ of distilled water to prepare $10 \%$ aqueous GT extract (GTE), which was given to rats by oral gavage [18].

Animals. Male Wistar rats were maintained under specific pathogen-free conditions at $22^{\circ} \mathrm{C}$ under a 12-hour light/dark cycle in the Animal House of Faculty of Medicine, Zagazig University, Egypt. All animals were fed a standard pelleted chow, and were given free access to water. Animals were maintained according to the guidelines for animal research issued by National Institute of Health and approved by Animal Ethics Committee, Zagazig University, Egypt.

Experimental design. The experiment was performed on sixty rats: thirty young-adult (6-month-old, body mass 200 $-220 \mathrm{~g}$ ) and thirty old (24-month-old, body mass 220-260 g) animals. Each group was further divided into two subgroups ( $\mathrm{n}=15$ each): control rats had free access to water and were additionally given $1.5 \mathrm{~mL}$ of distilled water daily by oral gavage for 14 weeks, whereas GT-treated rats received $1.5 \mathrm{~mL}(300 \mathrm{mg} / \mathrm{kg} /$ day $)$ of GT extract daily for 14 weeks by oral gavage according to Gad et al. [18].

The animals were euthanized under full anesthesia by intraperitoneal injection of sodium thiopental $(25 \mathrm{mg} / \mathrm{kg})$ according to Kara et al. [19]. The jejunum was carefully dissected by laparotomy and processed for light and electron microscopy and biochemical assays. 
For light microscopic examination tissue samples were fixed in $10 \%$ neutral formalin prior to sectioning into $5 \mu \mathrm{m}$-thick sections. Sections were stained with hematoxylin and eosin $(\mathrm{H} \& \mathrm{E})$ to evaluate general tissue morphology according to Bancroft et al. [20]. Mallory trichrome stain was used for the detection of collagen fibers, and PAS reaction was applied for histochemical detection of carbohydrates as described by Bancroft et al. [21].

Immunohistochemistry. Jejunal sections were placed on charged slides, and used for immunohistochemical (IHC) examination. Detection of proliferating cell nuclear antigen (PCNA) and cluster of differentiation 68 (CD68) antibodies was done using streptavidin-biotin complex immunoperoxidase system. Sections were incubated in $0.1 \%$ hydrogen peroxide for $30 \mathrm{~min}$ to block the endogenous peroxidase activity. Then they were incubated with PCNA Ab-1 (Clone PC10) mouse monoclonal (Cat. No. MS-106-PCS, Lab Vision Corp., Fremont, CA, USA), diluted 1:75 and applied to sections for $12 \mathrm{~h}$ at $4^{\circ} \mathrm{C}$ for the detection of PCNA. For the detection of CD68, the sections were incubated with mouse CD68/Macrosialin antibody (KP1) (Cat. No. MA513324, Lab Vision) diluted 1:200 in phosphate-buffered saline (PBS) for $30 \mathrm{~min}$. After several washes with PBS, sections were incubated with biotinylated goat anti-mouse IgG (Zymed Laboratories, South San Francisco, CA, USA) for $30 \mathrm{~min}$ at room temperature (RT). Thereafter, all sections were incubated with the streptavidin-biotin peroxidase complex for $30 \mathrm{~min}$ at RT. After washing with PBS, reactions were visualized with 3',3'-diaminobenzidine-tetrahydrochloride (DAB; Sigma-Aldrich, St. Louis, MO, USA) used as chromogen to visualize antibody binding. The sections were counterstained with Mayer's hematoxylin, dehydrated and mounted. For negative control, primary antibodies were replaced with PBS. Positive reaction for PCNA was nuclear one, whereas CD68 protein appeared as brown-yellow particles inside the cytoplasm [2,22].

Transmission electron microscopy. Specimens for electron microscopy were immediately fixed in $2.5 \%$ phosphate-buffered glutaraldehyde ( $\mathrm{pH} 7.4$ ) and post-fixed in $1 \%$ osmium tetroxide at $4^{\circ} \mathrm{C}$ followed by dehydration, and embedded in epoxy resin. Ultrathin sections were stained with uranyl acetate and lead citrate [23]. They were examined and photographed using a JEOL JEM 1010 electron microscope (Jeol Ltd, Tokyo, Japan).

Biochemical assays. Parts of the jejunum were homogenized for the estimation of the oxidative status. About $0.1 \mathrm{~g}$ of the frozen jejunum sample in ice-cold saline $(0.9 \% \mathrm{NaCl})$ solution was weighed. The proportion of saline $(\mathrm{mL})$ and jejunum sample $(\mathrm{g})$ was 9:1. The mixture of jejunal tissue and phosphate-buffered saline was homogenized using a tissue digital homogenizer (IKA Ultra-turax T25, Sigma-Aldrich) and the homogenate was then centrifuged at $3500 \mathrm{~g}$ for $10 \mathrm{~min}$. Finally, the supernatant was collected and stored at $-20^{\circ} \mathrm{C}$ for the detection of oxidative/antioxidative parameters.

Total antioxidant capacity (TAC) assay. Tissue TAC was determined using a commercial kit following the manufacturer's protocol (Biodiagnostic, Giza, Egypt) on the basis of the oxidation/reduction colorimetric assay at $532 \mathrm{~nm}$. The method is based on that the antioxidants in the sample eradicate a certain amount of the provided hydrogen peroxide. The remaining $\mathrm{H}_{2} \mathrm{O}_{2}$ is measured colorimetrically by an enzymatic reaction transforming 3,5-dichloro-2-hydroxyl benzenesulfonate to a color product.

Glutathione peroxidase (GPx) activity assay. GPx activities in tissue were measured according to manufacturer's protocol (Biodiagnostic, Obour City, Egypt). The rate of decrease in the absorbance at $340 \mathrm{~nm}$ is directly proportional to the GPX activity in the sample.

Malondialdehyde (MDA) assay. Measurements of MDA levels were done by a commercial chemical colorimetrical assay kit according to manufacturer's protocol (Biodiagnostic, Obour City, Egypt). MDA is a natural bi-product of lipid peroxidation; in the samples it reacts with thiobarbituric acid (TBA) to generate a MDA-TBA adduct. The MDA-TBA adduct can be quantified colorimetrically at $534 \mathrm{~nm}$.

Histomorphometry. All morphometric measurements were made using a Leica QWin 500 image analyzer (Leica, Wetzlar, Germany). Measurements were taken in 10 randomly selected non-overlapping fields from jejunal section of each animal according to the method described by Giblot et al. [24]. For the measurements only sections cut along the crypt's axis were used. All morphometric measurements were taken at total magnification of $\times 200$. Sections were evaluated as follow: 1) The heights of villi (from the tip of the villus to the junction of the villus and crypt; 2) Total thickness of the mucosa in $\mu \mathrm{m}$ (from the top of the villus to the muscularis mucosa); 3) The depths of crypts in $\mu \mathrm{m}$ (the subtraction of villus height from total mucosa thickness). Moreover, the numbers of PCNA and CD68 positively immunostained cells were counted at $\times 400$ magnification in 10 fields selected randomly.

Statistical analysis. Differences among the groups were analyzed via a one-way analysis of variance (ANOVA) followed by a Tukey-Kramer post-hoc test for inter-group comparisons using SPSS software v.16 (SPSS Inc., Chicago, IL, USA). All results were expressed as mean \pm standard deviation $(\mathrm{SD}), \mathrm{p}<0.05$ was considered statistically significant. 


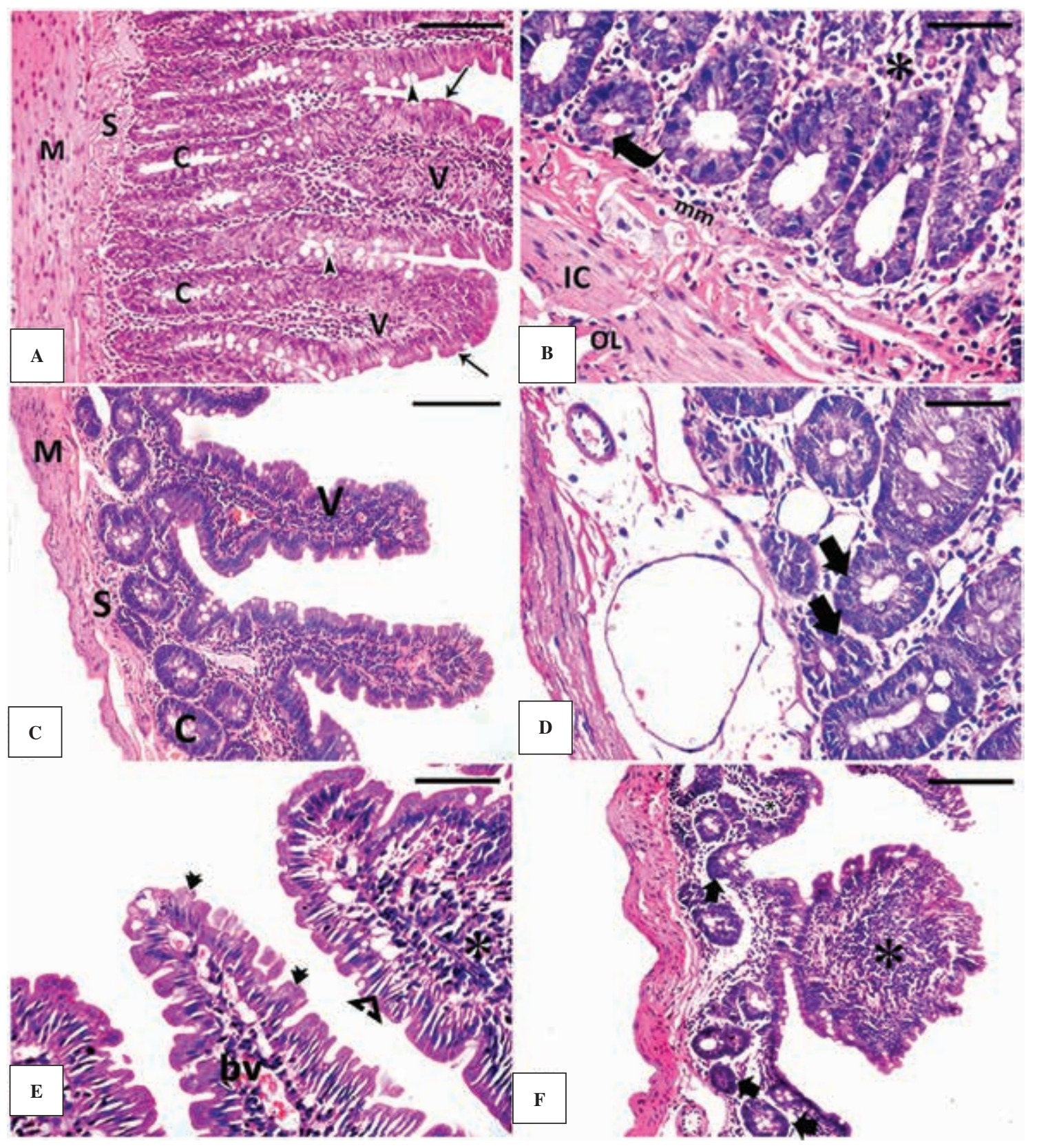

Figure 1. Morphology of the jejunum of young and old rats. A, B. Young control rat — the mucosa consisting of long and slender villi is covered by columnar absorbing cells with a brush border (arrows) and goblet cells (arrowheads). Paneth cells are lining the crypts (curved arrow). The lamina propria contains mononuclear cells (asterisks); C, D. The jejunum of old rat shows decreased number and length of intestinal villi and crypts. Distorted submucosa and attenuated muscularis externa can also be seen; E, F. The jejunum of old rat shows partial loss of acidophilic brush border (double arrowhead). Broad and blunt villus with disrupted epithelium and wide intercellular spaces (arrowhead). The crypt-lining cells are small with darkly stained nuclei (D, F; thick arrows). Abundant mononuclear cell infiltration in the lamina propria (asterisks) and congested blood vessels (bv) can be seen. Abbreviations: bv — blood vessels; C — crypts; IC — inner muscular layer; M — muscularis externa; mm - muscularis mucosa; OL - outer muscular layer; S - submucosa; V — villi. H \& E staining. Scale bars: A, C $-30 \mu \mathrm{m} ; \mathrm{B}, \mathrm{D}, \mathrm{E}, \mathrm{F}-50 \mu \mathrm{m}$.

\section{Results}

\section{Comparison of the morphology of the jejunal wall in young and old control rats}

The morphology of the jejunum of young control rats showed mucosa with long and slender villi covered by columnar absorbing cells tightly adherent to each other with a prominent brush border and goblet cells (Fig. 1A and Suppl. Fig. 1A, B). Intraepithelial lymphocytes could also be seen (Suppl. Fig. 1A). Intestinal crypts at the base of villi were surrounded by mucosal lamina propria which extended to the villous 


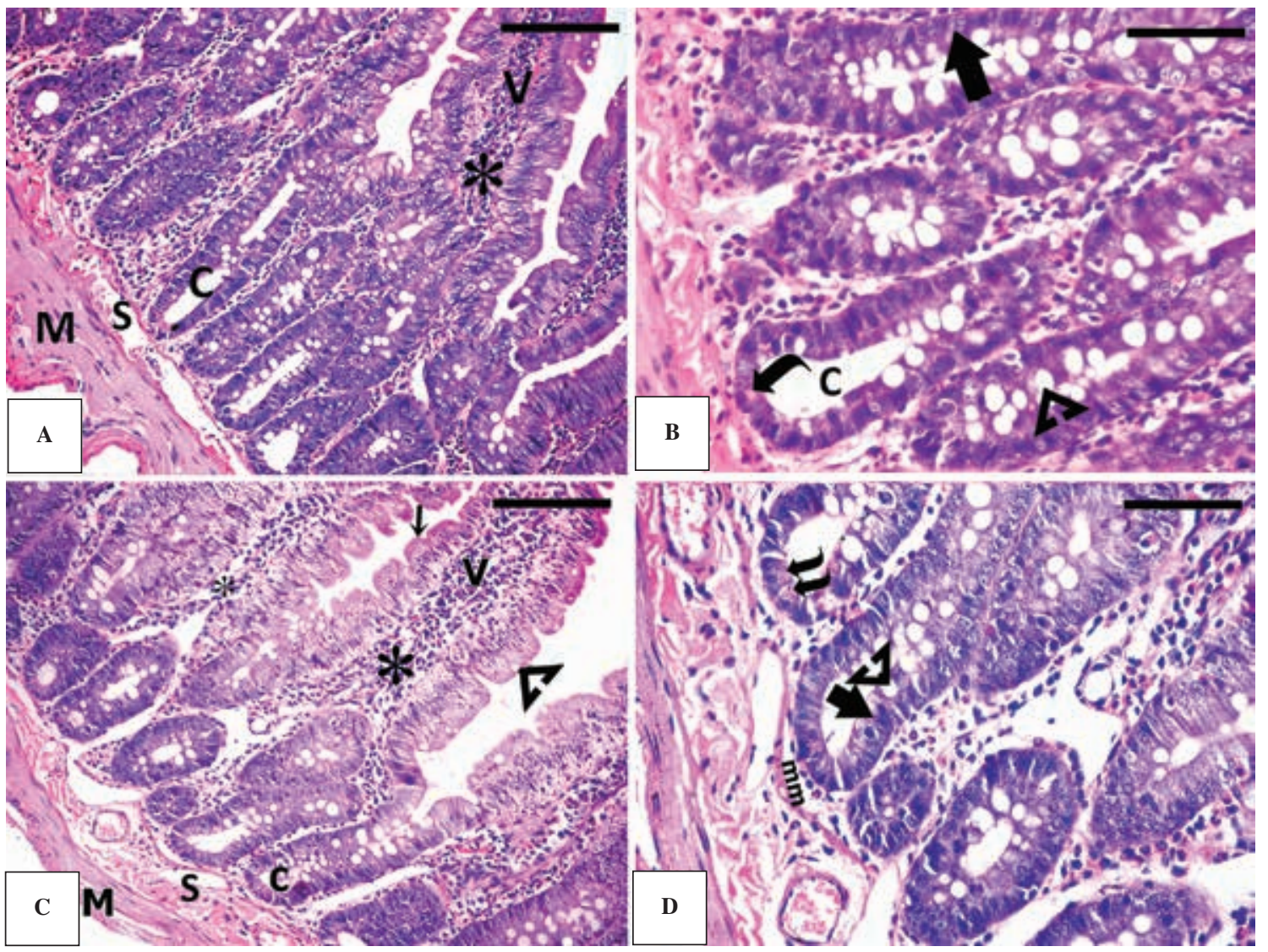

Figure 2. Morphology of the jejunum of young and old rats treated with green tea extract. The epithelium contains columnar cells with a brush border (arrow) and goblet cells (arrowheads). The crypts are lined with columnar absorbing cells (thick arrow), goblet cells (arrowhead) and Paneth cells (curved arrow). The lamina propria contains mononuclear cells (asterisks). A, B. Green tea extract-treated young rats; C, D. Green tea extract-treated old rats. Abbreviations as in the description of Figure 1 . H \& E staining. Scale bars: A and C $-30 \mu \mathrm{m}$; B and D $-50 \mu \mathrm{m}$.

core containing lacteals. Submucosa separates the mucosa from muscle layer (Fig. 1A and Suppl. Fig. 1A). Paneth cells with basal darkly-stained nucleus and acidophilic cytoplasm were seen at the base of the crypts. The lamina propria contained mononuclear cells. Muscularis externa was formed by inner circular and outer longitudinal smooth muscle cell layers (Fig. 1B).

Examination of the jejunal wall of old control rats showed decreased height of intestinal villi with spacing between adjacent enterocytes. Many intraepithelial lymphocytes (Suppl. Fig. 1C), distorted submucosa and attenuated muscularis externa were also observed (Fig. 1E, F). The villi showed partial loss of acidophilic brush border. Short, blunt and broad villi with disruption of their surface epithelium were also noticed. The epithelial lining cells of the crypts showed darkly-stained nuclei. Abundant mononuclear cell infiltration of the lamina propria and congested blood vessels were evident (Fig. 1C and Suppl. Fig. 1C).

Sections of young control rats displayed positive PAS reaction in the apical distended portion of gob- let cells (Fig. 3A), whereas jejunal epithelium of old control rats showed increased number of goblet cells with positive PAS reaction in the apical distended portion (Fig. 3C). In young control rats few mucosal and submucosal collagen fibers could be observed (Fig. 3E), whereas old rats showed many collagen fibers in the mucosa and submucosa (Fig. 3G).

\section{Comparison of the morphology of the jejunal wall in young and old rats treated with green tea extract} The examination of the GT extract-treated rats revealed nearly similar structure of the jejunal wall as in the control group (Figs. 2A, B; 3B, F; 4B, F; and Suppl. Fig. 1B). Examination of jejunal sections of rats treated with GT extract showed the mucosa consisting of long villi covered by columnar absorbing cells. Enterocytes were tightly adherent to each other, between some cells wide spaces were present. The absorptive cells showed basal oval nuclei and prominent nucleoli. Brush borders were also noticed. Many goblet cells and intraepithelial lymphocytes were visible. The crypts were lined with columnar absorbing cells, goblet 
cells and Paneth cells. The lamina propria contained mononuclear cells (Fig. 2C, D and Suppl. Fig. 1D). Old GT extract-treated rats showed positive PAS reaction in the apical distended portion of goblet cells (Fig. 3D) and some collagen fibers in the mucosa and submucosa (Fig. 3H).

\section{The presence of proliferating cells and monocytes/ /macrophages in the jejunal mucosa of control and green tea extract-treated young and old rats}

IHC staining for PCNA in the control (Fig. 4A) and GT extract-treated (Fig. 4B) young rats showed increased number of immunopositive nuclei of the crypt-lining cells. Decreased number of immunoreactive nuclei were detected in crypt cells of old control rats (Fig. 4C); however, increased number of PCNA-positive nuclei was observed in crypt cells of old GT-treated rats (Fig. 4D).

The IHC staining of control (Fig. 4E) and GT-treated rats (Fig. 4F) revealed few CD68-positive cells scattered all over the lamina propria. However, in the mucosa of old control rats many cells distributed throughout the lamina propria displayed CD68 immunoreactivity (Fig. 4G). Few CD68-positive cells were scattered over the lamina propria of GT extract-treated old rats (Fig. 4H).

\section{Ultrastructure of the jejunal mucosa of young and old control rats}

Electron microscopic examination of young rat's jejunum revealed adjacent columnar absorbing cells with numerous long microvilli in the luminal surface with terminal web at the apical cytoplasm. The cells presented oval basal electron-lucent nuclei and prominent nucleoli; their cytoplasms were abundant in mitochondria and rER cisternae. The neighboring cells were firmly adherent by complex junction (Fig. 5A, B). Goblet cells showed basal oval nuclei and prominent nucleoli, apical electron-dense secretory granules and cytoplasm was rich in rER cisternae. Enteroendocrine cells contained basal electron-dense secretory granules. All cells were resting on thin basal lamina (Fig. 5C, D). Paneth cells with electron-dense granules and irregular heterochromatic nucleus were also detected in the crypts. The lamina propria contained collagen fibers, lymphocytes, mast cells with many electron-dense granules. Eosinophils with characteristic ellipsoid granules were also detected (Fig. 5E, F).

Ultrastructural examination of the jejunum of old rats revealed columnar absorbing cells with wide spaces between adjacent cells. Degenerated goblet cells appeared with dilated $\mathrm{rER}$ cisternae. All cells were resting on thick basal lamina. The columnar absorbing cells showed few degenerated microvilli with formation of blebs. Apical cytoplasm showed many lysosomes and a multivesicular body (Fig. 6A, B). Paneth cells showed few electron-dense secretory granules (Fig. 6C). The lamina propria showed many collagen fibers, lymphocytes and mast cells with many electron-dense granules. Eosinophils with bi-lobed nucleus and characteristic ellipsoid granules could also be seen (Fig. 6D).

\section{Ultrastructure of the jejunal mucosa of green tea extract-treated young and old rats}

The jejunal epithelium of GT extract-treated young rats demonstrated columnar absorbing cells with basal oval electron-lucent nuclei and prominent nucleoli. The cytoplasm contained many mitochondria and rER cisternae. In the apical region of columnar absorbing cells long cylindrical microvilli, terminal web and junctional complex were present (Fig. 7A, B). Paneth cells with electron-dense granules were detected (Fig. 7C). The lamina propria contained thin basement membrane with blood capillaries and fibroblasts located below (Fig. 7D).

Electron microscopic examination of old GT-treated rats revealed the presence of adjacent columnar absorbing cells with numerous long microvilli. The neighboring cells were closely adjacent to each other. They contained basal oval electron-lucent nuclei. They were firmly adherent by junctional complex. Moreover, Paneth cells with many electron-dense granules and adjacent enterocytes with relatively narrow intercellular spaces between them were observed (Fig. 8A). The lamina propria contained collagen fibers and eosinophils with characteristic ellipsoid granules. Blood capillary with thick irregular basement membrane was also noticed (Fig. 8D).

\section{Histomorphometry of the rat jejunal mucosa in the studied model}

The histomorphometric measurements of the height of villi, depth of crypts and mucosal thickness are presented in Table 1. There was a significant decrease in these parameters in the jejunal mucosa of old control rats compared to the young control rats. Contrary, in the group of old rats treated with GT, there was a significant increase in all three measured parameters as compared to old control rats.

The number of PCNA-positive cells was significantly decreased in old control rats as compared with the young control rats. We observed a significant increase in the number of PCNA-positive cells in old rats treated with GT extract as compared to old control rats (Table 1). Moreover, the old control rats showed a significant increase in the number of CD68-positive cells as compared to the young control rats. On the other hand, treatment of old rats with 

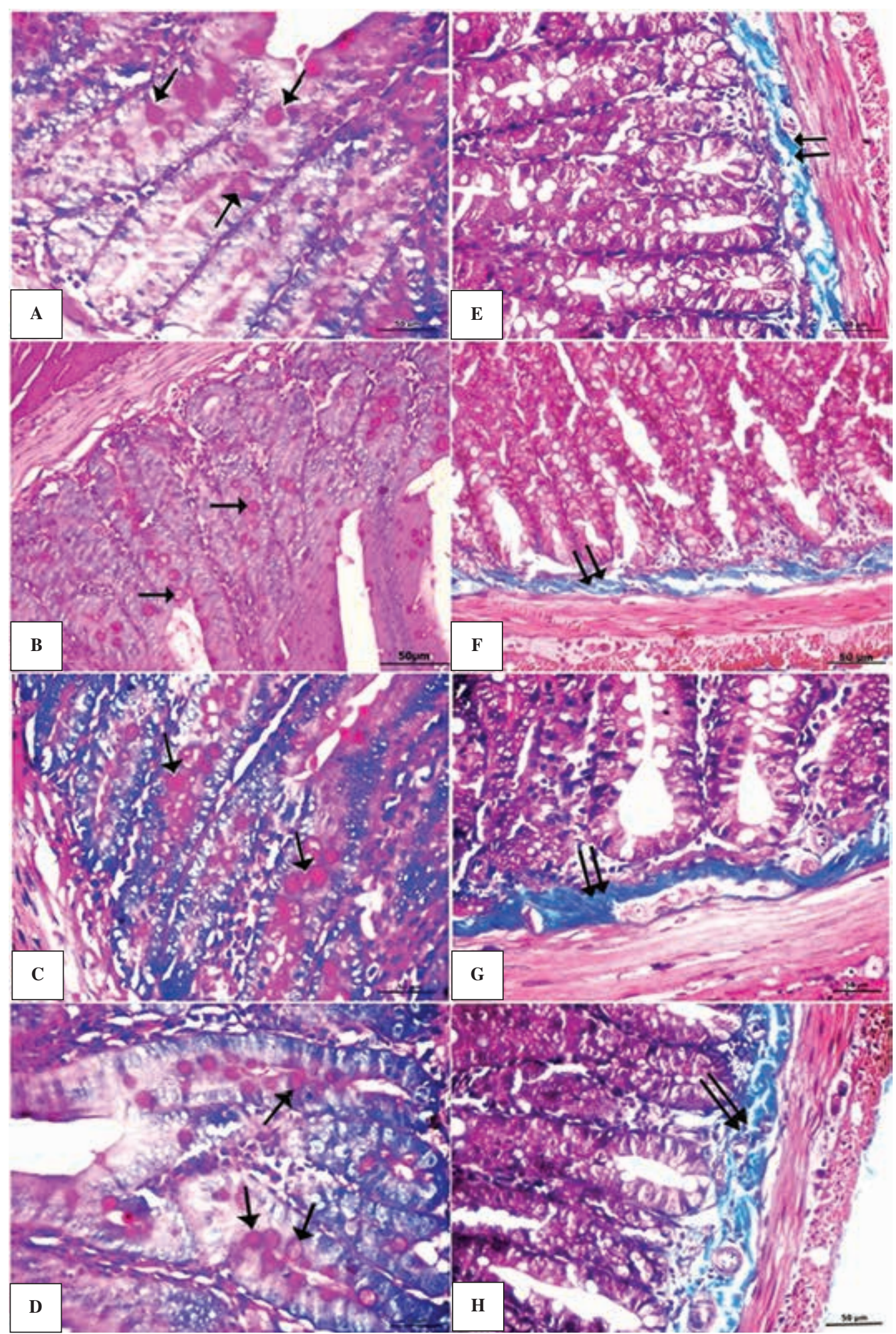

Figure 3. Morphology of the jejunum of rats stained by the PAS and Mallory methods. A. Young control rat; B. The jejunum of green tea-treated young rat showing positive PAS reaction in the apical distended portion of goblet cells (arrow); C. Old control rats - microscopic examinations revealed increased number of goblet cells with positive PAS reaction (arrow); D. The jejunum of green tea-treated old rat showing positive PAS reaction (arrow); E, F. Young control rats - microscopic examinations revealed few collagen fibers (double arrows) in the mucosa and submucosa; G. The jejunum of green tea extract-treated old rat showing some collagen fibers (double arrows) in the mucosa and submucosa; H. Old control rats showed many collagen fibers (double arrows) in the mucosa and submucosa. PAS staining: A-D. Mallory trichrome staining: E-H. Scale bars: $50 \mu \mathrm{m}$. 


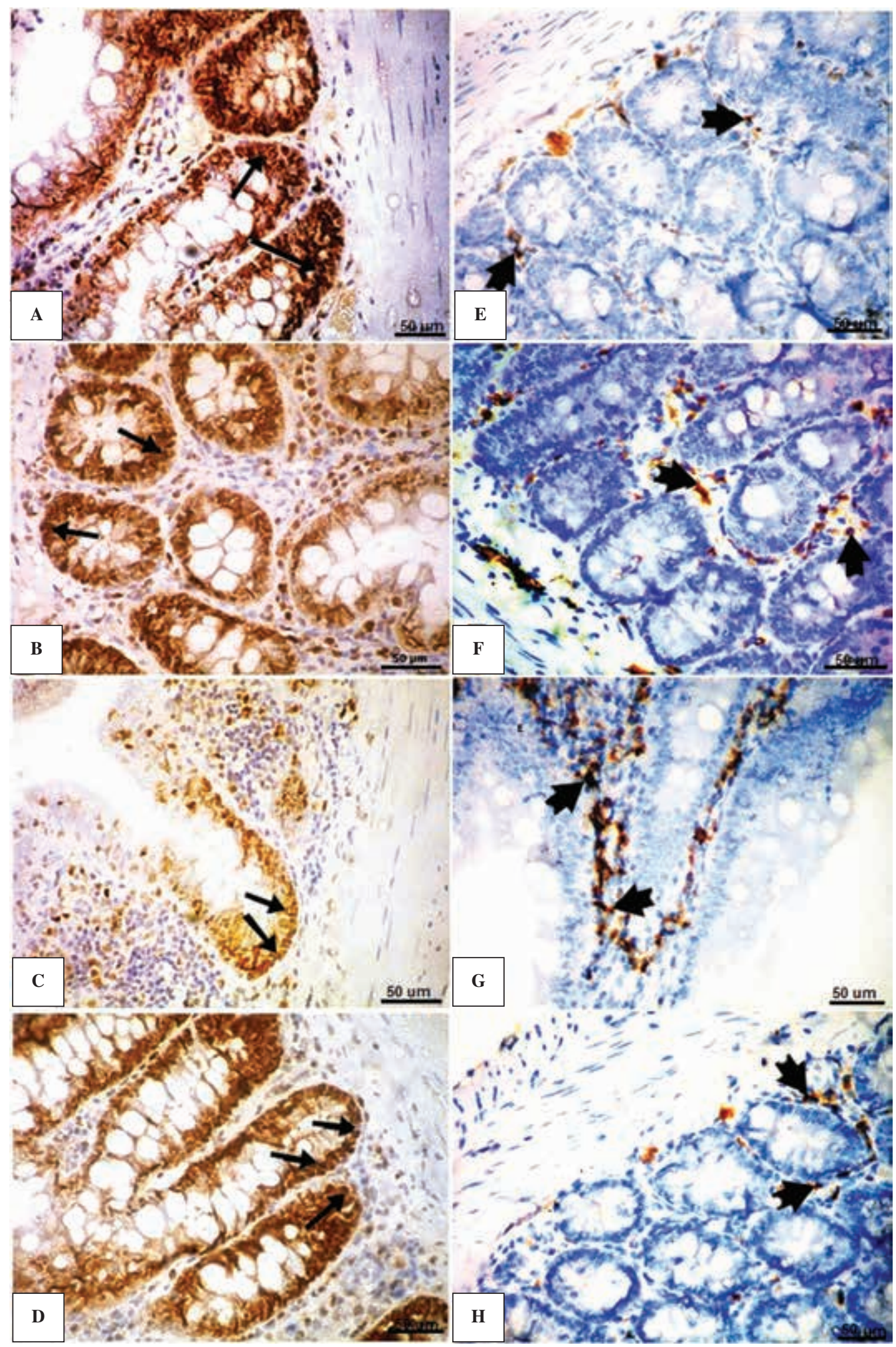

Figure 4. PCNA and CD68 immunoreactivity in the jejunum of young and old rats. A. Young control rats; B. Green tea extract-treated young rats - microscopic examinations revealed intense positive PCNA immunoreactivity (Ir) in the nuclei of crypt cells (arrow); C. Control old rats - microscopic examinations revealed weak PCNA Ir in the nuclei of crypt cells (arrow); D. The jejunum of green tea extract-treated old rats shows positive PCNA Ir in the nuclei of crypt cells (arrow); E, F. Young control rats - microscopic examinations revealed few $\mathrm{CD} 68^{+}$macrophages (thick arrow) distributed throughout the lamina propria; G. The jejunum of old control rats showing intense CD68 ${ }^{+} \mathrm{Ir}$ in many macrophages (thick arrow) distributed throughout the lamina propria; $\mathbf{H}$. The jejunum of green tea extract-treated old rats showing few $\mathrm{CD} 68^{+}$macrophages (thick arrow) in the lamina propria. Immunochemical staining was performed as described in Material and methods. Scale bars: $50 \mu \mathrm{m}$. 

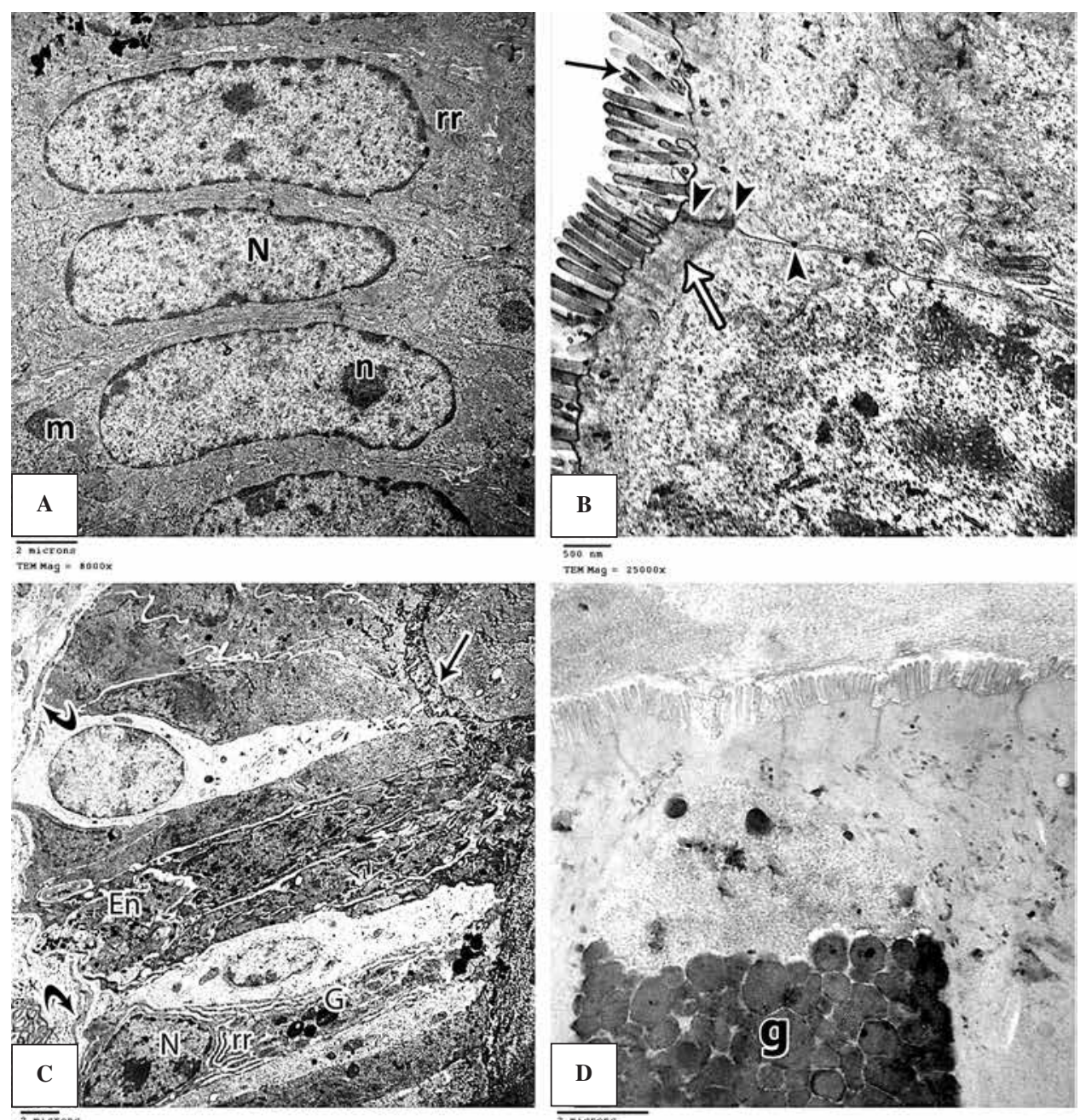

2 Recrons
Tex Mag
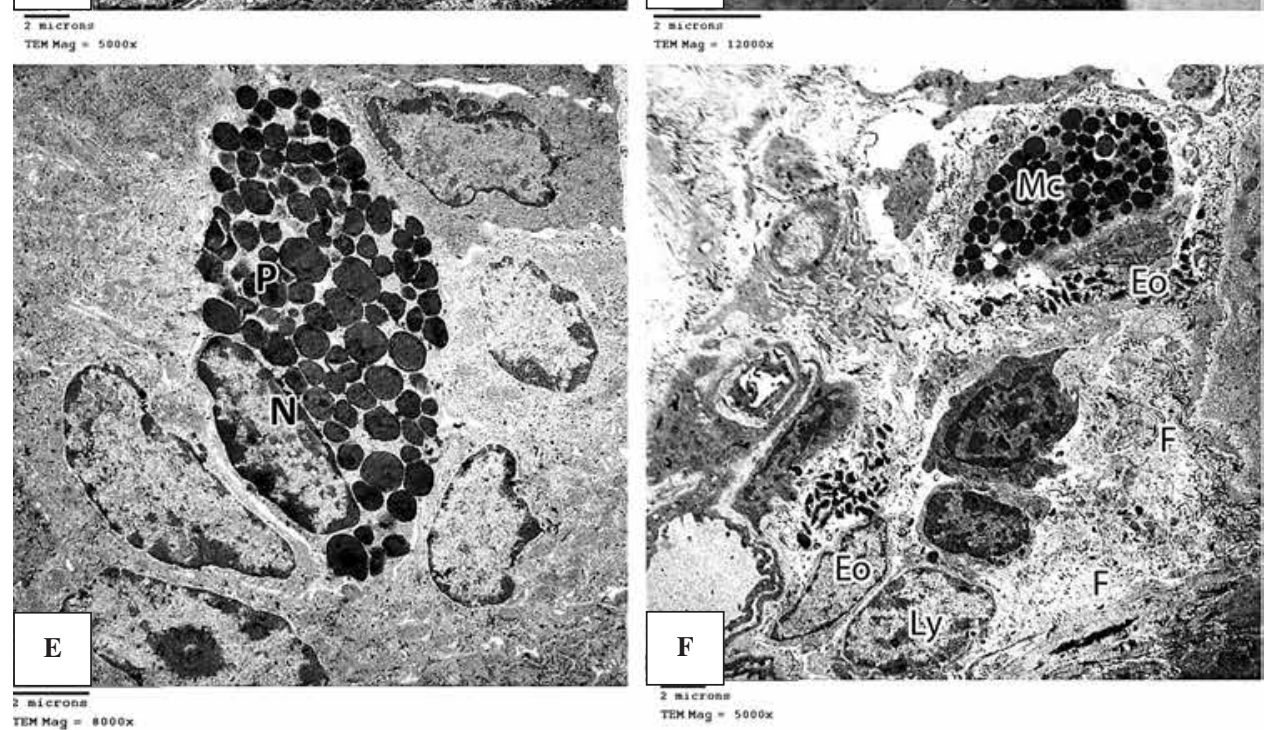

Figure 5. Ultrastructure of the jejunal epithelium of young control rats. A, B. The adjacent columnar absorbing cells are firmly adherent to each other due to junctional complex (arrowheads). Long cylindrical microvilli (arrow) and terminal web at the apical cytoplasm (white arrow) are also seen. They have basal oval electron-lucent nuclei (N) and prominent nucleoli (n). The cytoplasm is rich in mitochondria (m) and RER cisternae (rr); C, D. Goblet cells have basal oval nucleus with prominent nucleolus (N), electron-dense secretory granules (g) and their cytoplasm is rich in RER cisternae (rr). Part of an enteroendocrine cell (En) contains basal electron-dense secretory granules (En). The cells rest on thin basal lamina (curved arrow); E, F. Paneth cells with electron-dense granules (P) and irregular heterochromatic nucleus (N); lamina propria contains collagen fibers (F), lymphocytes (Ly), mast cell with many electron-dense granules (Mc). Eosinophils with characteristic ellipsoid granules are present (Eo). Scale bars: A, C-F $-2 \mu \mathrm{m}$; B $-500 \mathrm{~nm}$. 

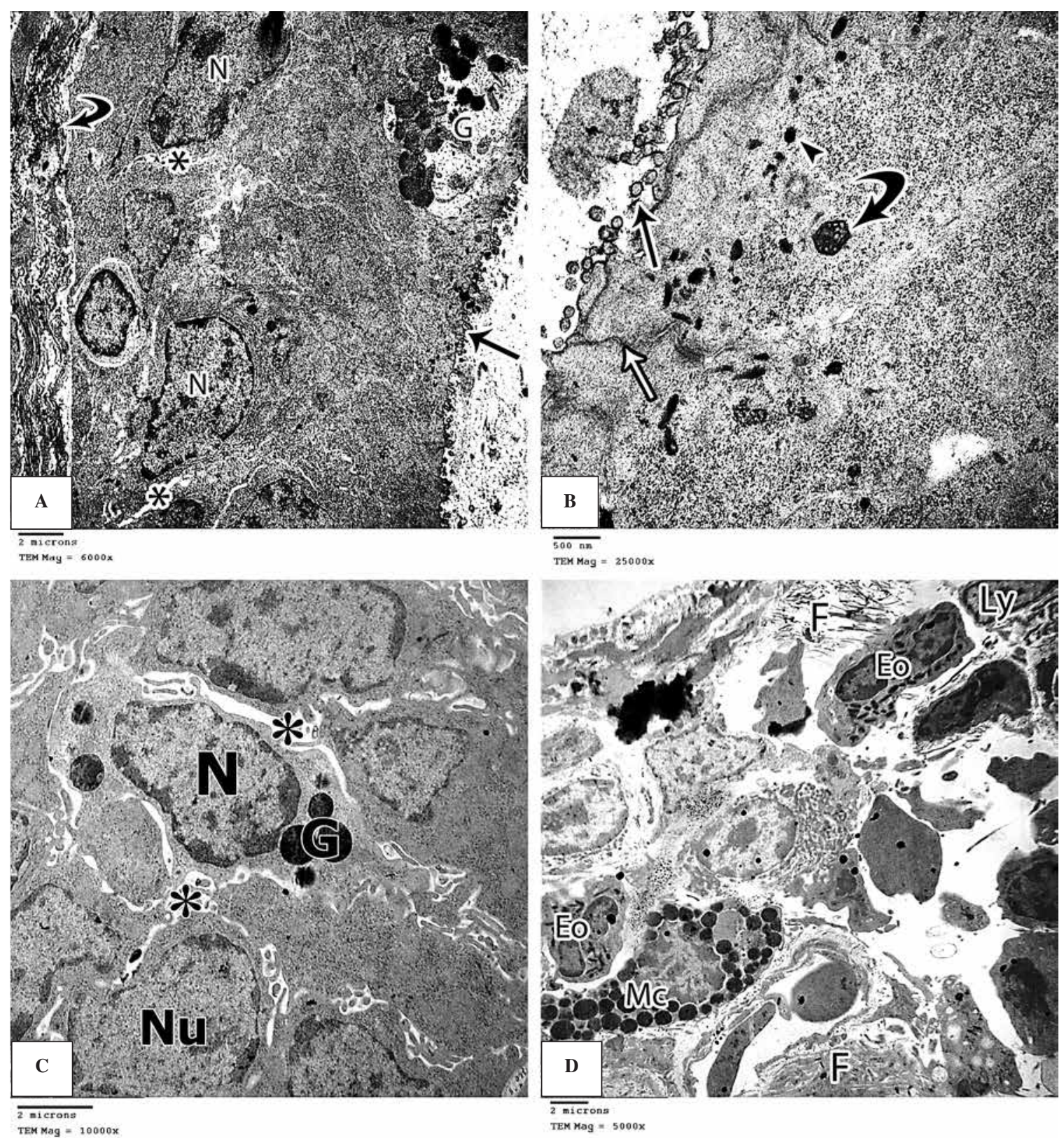

Figure 6. Ultrastructure of the jejunal epithelium of old control rats. A, B. The adjacent columnar absorbing cells present degenerated microvilli (arrow) and irregular heterochromatic nuclei (N). Apical cytoplasm contains numerous lysosomes (arrowhead) and multivesicular body (curved arrow in B). The enterocytes are bound by tight junction and desmosomes (white arrow). Part of degenerated goblet cell with dilated $\mathrm{rER}$ cisternae $(\mathrm{G})$ could be noticed. Widened intercellular spaces between adjacent cells (asterisks) could be seen. The cells rest on thick basal lamina (curved arrow in A); C, D. Paneth cells contain few electron-dense granules $(\mathrm{G})$ and irregular heterochromatic nucleus $(\mathrm{N})$. Lamina propria contains collagen fibers (F), lymphocytes (Ly), mast cells with many electron-dense granules (Mc). Eosinophils with bi-lobed nucleus and characteristic ellipsoid granules could be seen (Eo). Scale bars: A, C, D $-2 \mu \mathrm{m}$; B $-500 \mathrm{~nm}$.

GT extract significantly decreased the number of CD68-positive cells in the jejunal mucosa as compared to old control rats (Table 1).

\section{Oxidative status of rat jejunal mucosa in the studied model}

Total antioxidative capacity and glutathione peroxidase activity were significantly lower in the jejunal homoge- nates of old control rats as compared with the young control rats (Table 2). MDA levels were significantly higher in the jejunum of old control rats than in young rats. A significant increase in the antioxidant parameters (TAC and GPx) was found in GT extract-treated old rats as compared to control group of old rats. Moreover, the treatment of old rats with GT extract significantly decreased MDA levels in the jejunum (Table 2). 

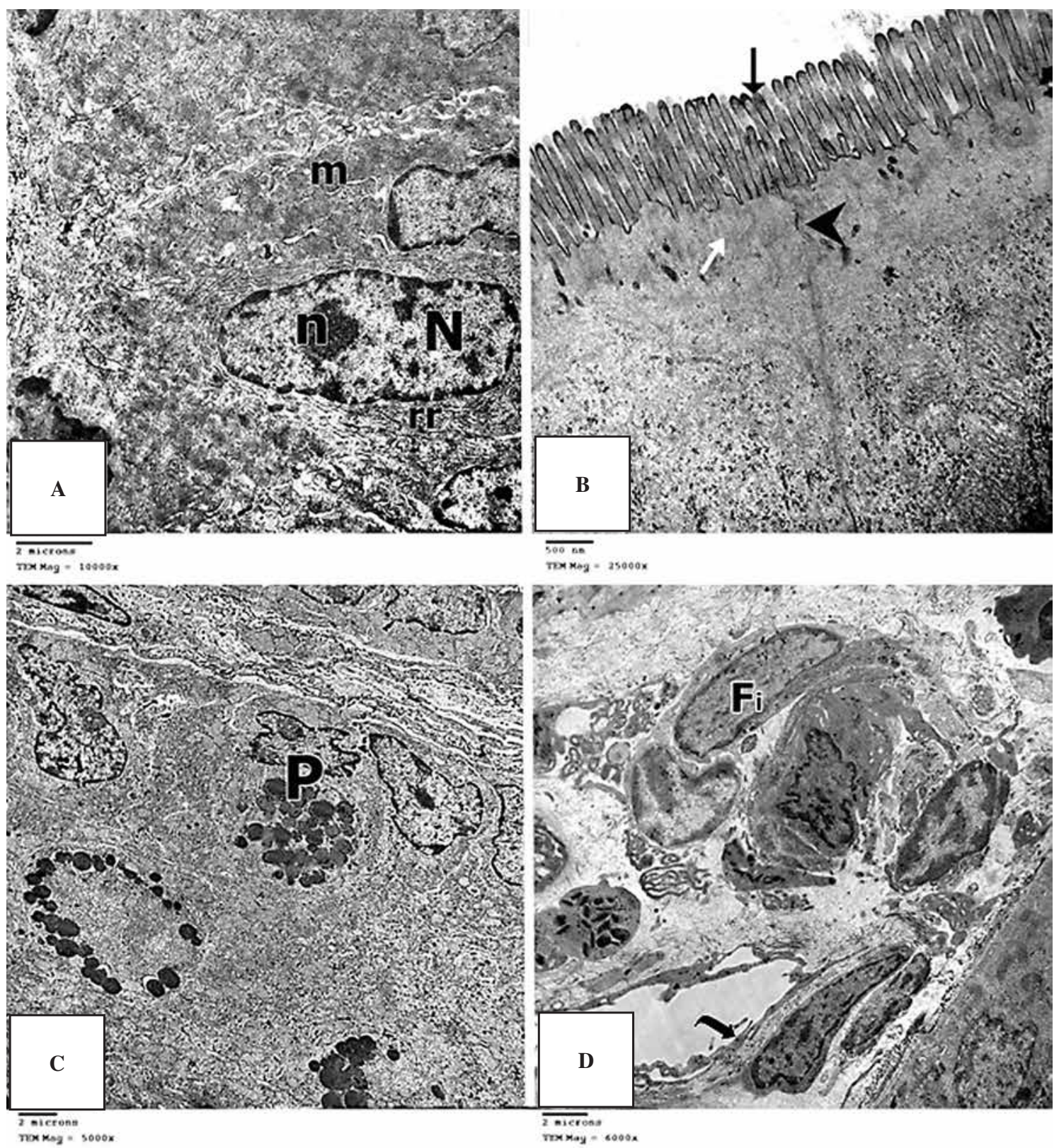

Figure 7. Ultrastructure of the jejunal mucosa of the green tea extract-treated young rats. A, B. Columnar absorbing cells contain numerous long cylindrical microvilli (arrows), terminal web (white arrow), basal oval electron-lucent nucleus (N) and prominent nucleolus (n). The cytoplasm is rich in mitochondria (m) and RER cisternae (rr). Junctional complexes were found between neighboring cells (arrowheads); C. Paneth cell $(\mathrm{P})$ with electron-dense granules and irregular heterochromatic nucleus (N); D. Lamina propria contains fibroblasts (Fi) and blood capillary with thin basement membrane (curved arrow). Scale bars: A, C, D $-2 \mu \mathrm{m}$; B $-500 \mathrm{~nm}$.

\section{Discussion}

Specific age-related malabsorption, resulting from the altered function of gastrointestinal mucosa, and maldigestion are two main causes of senile undernutrition [25].

The main finding of our study was the demonstration that GT extract administration effectively ameliorated age-related alterations in the jejunum of old rats, and that this effect might have been related to the antioxidative components of green tea.

In the current study, old rats showed decreased thickness of the mucosa including intestinal villi and depth of crypts with disruption of the surface epithelium in short villi. These findings are in agreement with Baum et al. [26] who reported in a dog a strong correlation between age and thickness of the intestinal wall. They found an age-related reduction 

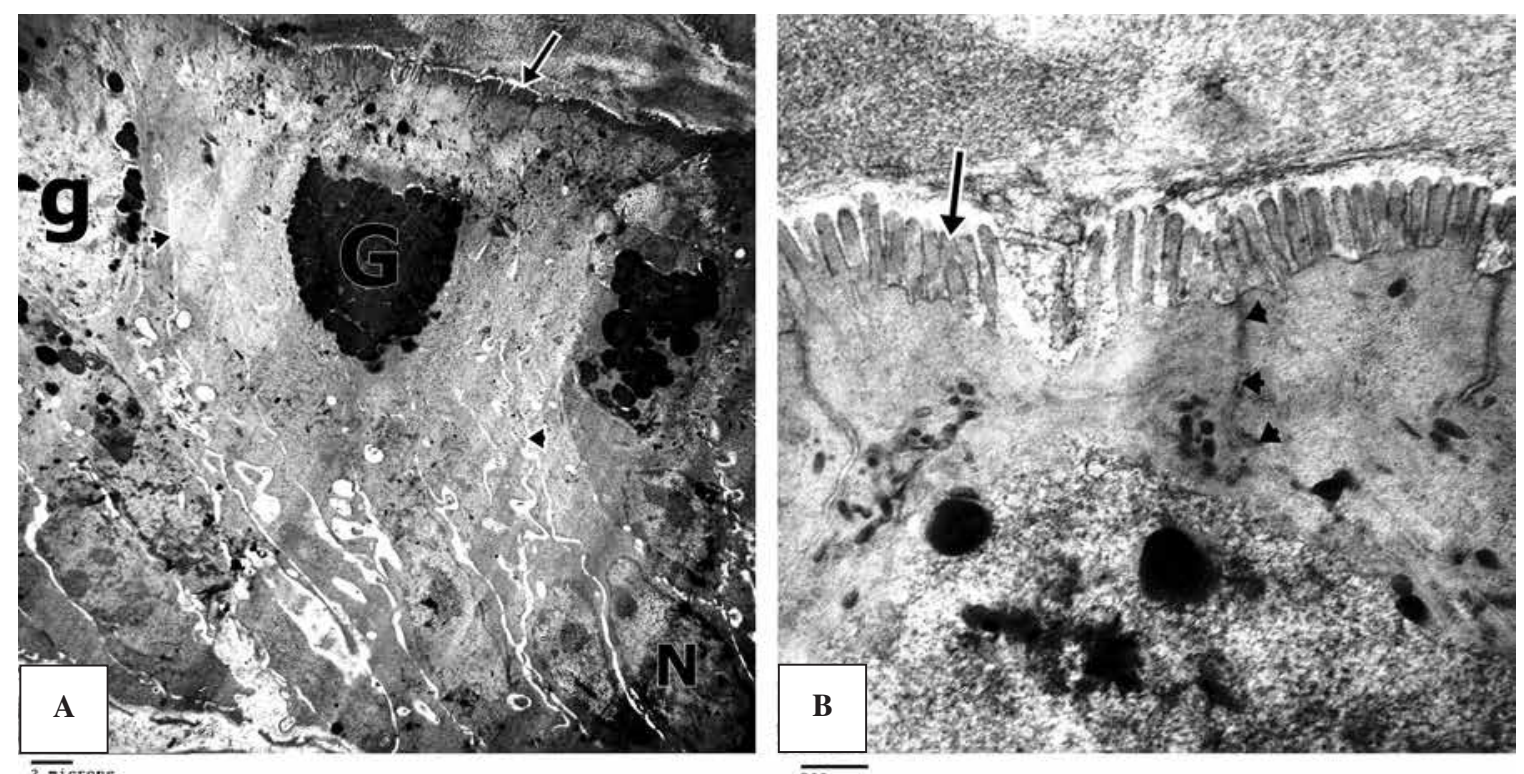
TEicrons
TER Mag $={ }_{4000 x}$
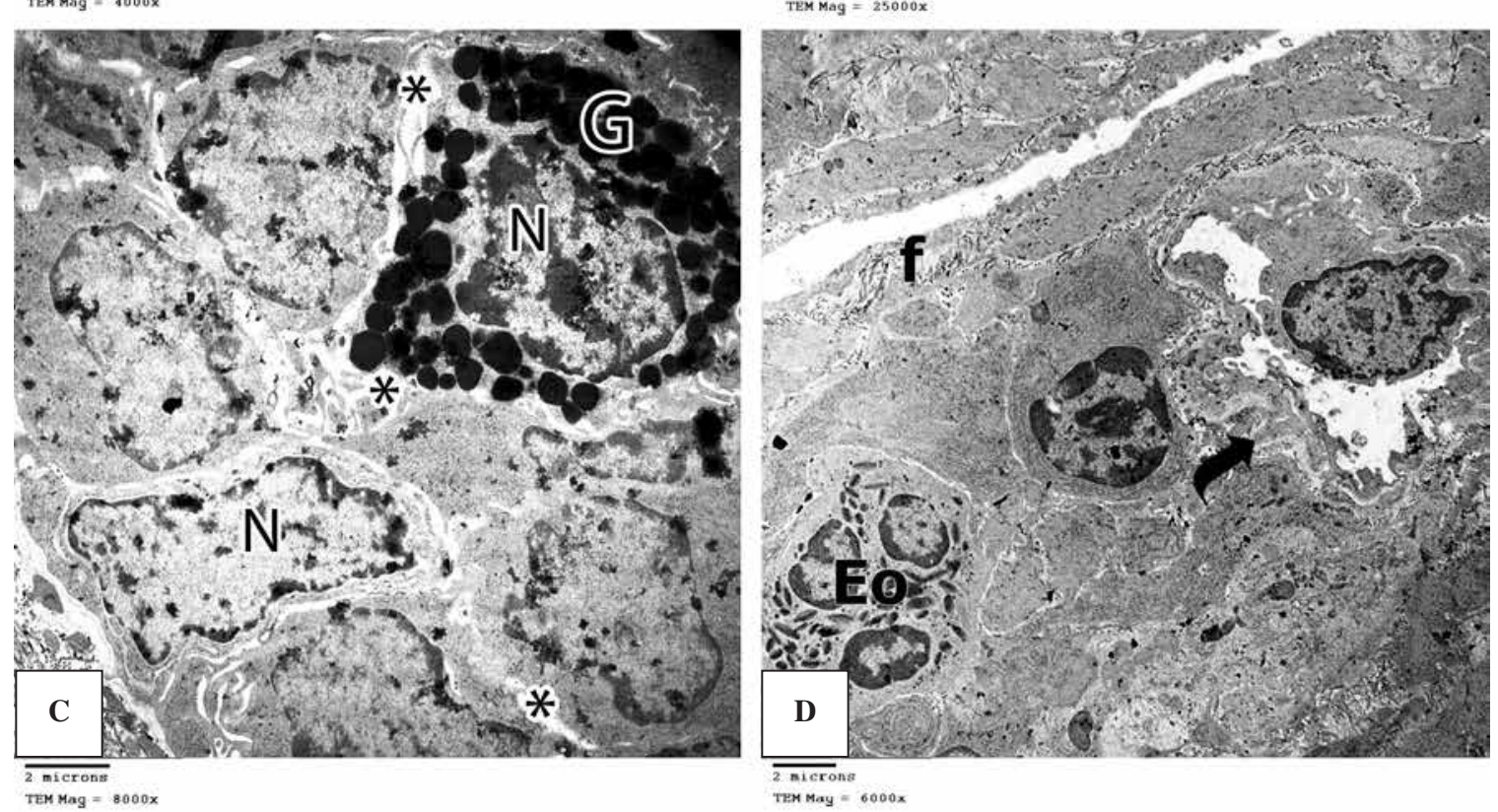

Figure 8. Ultrastructure of the jejunal mucosa of green tea extract-treated old rats. A, B. Enterocytes, closely adjacent to each other (arrowheads) present numerous long microvilli (arrows) and oval electron-lucent nuclei (N); C, D. Paneth cell appeared with many electron-dense granules $(\mathrm{G})$ and irregular heterochromatic nucleus $(\mathrm{N})$. Adjacent enterocytes show irregular heterochromatic nuclei $(\mathrm{N})$ with relatively narrow intercellular spaces (asterisks). Collagen fibers (F), and eosinophils with characteristic ellipsoid granules (Eo) as well as blood capillary with thick irregular basement membrane (curved arrow) are seen in the lamina propria. Scale bars: A, C, D $-2 \mu \mathrm{m}$; B $-500 \mathrm{~nm}$.

in the height of villi and the surface area of intestinal mucosa. On the contrary, Martin et al. [27] found that the mean thickness of all layers of the murine jejunum increased with age. Holt et al. [28] noticed increases in the width of villi over the small intestine of old Fischer 344 rats. They found increased villus height with decrease in the number of villi and crypts in aged rats [28]. Interestingly, no age-related changes of intestinal mucosa were found in humans [29].
In our study, we report preservation of the normal mucosal structure of jejunum of GT extract-treated old rats. In line with the potential role of green tea administration, previous studies reported that polyphenol-rich extracts induced an increased villus height to crypt depth ratio in jejunum of weaned pigs [30]. They believed that polyphenols might recover the digestibility of nutrients owing to the increase in absorptive surface of the intestine [30]. Similar con- 
Table 1. Histomorphometrical measures of the height of villi, depth of crypts, total mucosal thickness, number of PCNA-positive and CD68-positive cells

\begin{tabular}{|l|c|c|c|c|}
\hline \multirow{2}{*}{} & \multicolumn{2}{|c|}{ Young rats } & \multicolumn{2}{c|}{ Old rats } \\
\cline { 2 - 5 } & Control group & $\begin{array}{c}\text { Rats treated with } \\
\text { green tea extract }\end{array}$ & Control group & $\begin{array}{c}\text { Rats treated with } \\
\text { green tea extract }\end{array}$ \\
\hline Crypt depth $[\mu \mathrm{m}]$ & $984.3 \pm 243.0$ & $980.5 \pm 239.7$ & $577.2 \pm 189.6^{*}$ & $905.4 \pm 151.6^{\#}$ \\
\hline Villus height $[\mu \mathrm{m}]$ & $932 \pm 185.5$ & $933.6 \pm 183.2$ & $707.9 \pm 101.3^{*}$ & $889.6 \pm 92.8^{\#}$ \\
\hline Thickness of the mucosa $[\mu \mathrm{m}]$ & $1914.4 \pm 156.7$ & $1917.1 \pm 158.3$ & $1285.0 \pm 112.5^{*}$ & $1795.0 \pm 82.7^{* \#}$ \\
\hline PCNA+ $\left[\right.$ cells $\left./ \mathrm{mm}^{2}\right]$ & $0.39 \pm 0.07$ & $0.43 \pm 0.03$ & $0.08 \pm 0.01^{*}$ & $0.33 \pm 0.04^{\#}$ \\
\hline CD68+ $\left[\right.$ cells $\left./ \mathrm{mm}^{2}\right]$ & $50.3 \pm 15.2$ & $55.3 \pm 14.5$ & $78.4 \pm 14.8^{*}$ & $56.5 \pm 12.3^{\#}$ \\
\hline
\end{tabular}

Data are expressed as mean and SD. *Significantly different from the young control group, $\mathrm{p}<0.05$; \#Significantly different from the old control group, $\mathrm{p}<0.05$.

Table 2. The mean values of the level of total antioxidant capacity (TAC), malondialdehyde (MDA) and glutathione peroxidase (GPx) activities in the jejunal mucosa of young and old rats

\begin{tabular}{|l|c|c|c|c|}
\hline \multirow{2}{*}{} & \multicolumn{2}{|c|}{ Young rats } & \multicolumn{2}{c|}{ Old rats } \\
\cline { 2 - 5 } & Control group & $\begin{array}{c}\text { Rats treated with } \\
\text { green tea }\end{array}$ & Control group & $\begin{array}{c}\text { Rats treated with } \\
\text { green tea }\end{array}$ \\
\hline TAC [mmol/mg protein] & $0.96 \pm 0.09$ & $0.92 \pm 0.06$ & $0.63 \pm 0.05^{*}$ & $0.88 \pm 0.07^{\#}$ \\
\hline GPx [U/mg protein] & $0.89 \pm 0.07$ & $0.89 \pm 0.03$ & $0.32 \pm 0.06^{*}$ & $0.92 \pm 0.06^{\#}$ \\
\hline MDA [nmol/mg protein] & $0.63 \pm 0.05$ & $0.65 \pm 0.04$ & $1.26 \pm 0.09^{*}$ & $0.58 \pm 0.04^{\#}$ \\
\hline
\end{tabular}

Data are expressed as mean and SD. *Significantly different from the young control group, $\mathrm{p}<0.05$; ${ }^{\#}$ Significantly different from the old control group, $\mathrm{p}<0.05$.

clusions were drawn by Frejngel and Wroblewska, who examined the physiological effect of high doses of polyphenol extracts from green tea on nutrient absorption and digestibility in rats [31].

In the presented study, sections of the jejunal mucosa of old control rats revealed increased number of goblet cells at the age of 24 months, whereas in GT extract-treated old rats the number of goblet cells was reduced to the normal level. These findings, confirmed by PAS reaction, are consistent with Wang et al. [2] who reported an increased number of goblet cells in 12-month-old rats, which was associated with an increase in mucus secretion. They concluded that the increased number of goblet cells might be a protective mechanism against the malfunction of digestive tract in aged rat. In streptozotocin-treated rats GT extract improved the histological structure of the small intestine and stimulated the changes in the goblet cells distribution in small intestine [32].

The old rats' lamina propria showed heavy infiltration of mononuclear cells and presence of collagen fibers, which returned to the normal state after GT extract administration. Kang et al. [33] found increased deposition of connective tissue and collagen in the rat's gastric mucosa with aging. It was suggested that accumulation of oxidative products during aging contributes to increased deposition of connective tissue and replacement of mucosal tissue [34]. A study in 10 month-old mice showed that green tea postponed age-related collagen deposition by an antioxidant mechanism that interrupts collagen cross-linking in tendons and skin [35].

PCNA is strongly associated with the nuclear regions where DNA synthesis occurs; thus, it can objectively reflect the rate of cell proliferation [2]. In the current study, the number of PCNA-positive cells was significantly lower in the crypts of old control rats than in young control rats. This age-related decrease was reversed by the prolonged treatment of old rats with green tee extract. Wang et al. [2] found that the proliferation index of $\mathrm{PCNA}^{+}$cells in the intestinal crypts decreased in rats in $12^{\text {th }}$ postnatal month. On the contrary, Holt and Yeh [36] demonstrated that duodenal, jejunal, and ileal crypt cell production rates were increased in old male Fischer rats fed using the vincristine-induced metaphase arrest technique. This suggests that small intestinal cell production is enhanced in senescent rats compared to young rats fed the same diet and kept under the same living conditions. The discrepancies between our results and those of Holt and Yeah [36] may be attributed to differences between the strains of rats or applied techniques. However, a study performed by Xiao et al. [37] on Fischer 344 rats showed that aging is associated with increased 
proliferation and decreased apoptosis in the colonic mucosa.The increased number of PCNA-positive cells in the jejunum of GT extract-treated old rats might be attributed to the ability of green tea polyphenols to increase DNA synthesis and promote cellular differentiation due to the regulation of pro-survival and cell differentiation factors at the transcriptional and/ or translational level [38].

The CD68 protein is widely recognized as a marker of monocytes/macrophages, neutrophils and large lymphocytes with the predominant presence on macrophages [39]. Interestingly, only few studies dealing with the measurement of the number of mononuclear cells in the small intestine during aging have been performed. Whereas we found higher number of the CD68-immunopositive cells in the lamina propria of old control rats than in young rats, Kleinschmidt et al. demonstrated decreased number of MAC387-positive macrophages in the small intestine of senescent dogs [40]. Since macrophages play a major role in the protective responses to bacteria and antigens that reach the epithelium, our finding that the administration of GT extract returned the number of CD68-positive cells to the level found in young control rats suggests that green tea components may increase the immunoprotective function of the small intestine in aging.

In the present study, the columnar absorbing cells showed few degenerated microvilli with formation of blebs with many apical lysosomes and a multivesicular body. Confirming this result, Jang et al. [41] found by electron microscopic examination that there were less dense brush border membranes in the duodenum of old rats than in young control group. The authors attributed this finding to the specific activities of alkaline phosphatase (ALP) and gamma-glutamyl transpeptidase (gamma-GT) which were significantly increased with age [41].

Aging is frequently caused by many pathological conditions and some related phenomena such as increased lipid peroxidation, generation of free radicals, and increased peroxidation of nitric oxide resulting from oxidative stress [42]. Alterations in glutathione-dependent antioxidant system may affect the physiological and metabolic functions of cellular membranes. Generally, the aging process enhances lipid peroxidation and disruption of membrane structure [43]. In this work, a significant decrease in the activities of antioxidant parameters (TAC and GPX activity) in the old rats' jejunum and a significant increase in MDA levels were observed. By the administration of the green tea extract to old rats, these parameters recovered to normal values of young rats. This effect can be attributed to the antioxidative activity of green tea, since its administration prevented decreases in liver glutathione (GSH) concentrations induced by ethanol administration [44]. A previous study showed that green tea extract has the capacity to scavenge free radicals with significant increase in the activity of antioxidant enzymes such as glutathione S-transferases (GST), superoxide dismutase (SOD) and GPX [45]. Administration of GT extract resulted in considerable improvement in lipid peroxidation and protected lipids against peroxidation in tamoxifen-intoxicated rats [45]. The general cancer-preventive activities of green tea in animal models have been comprehensively described by Yang et al. [46].

In this study we have also revealed increased prevalence of intercellular spaces between adjacent enterocytes in old rats' jejunum. Ren et al. found that tight junctions (TJ) of intestinal epithelial cells were wider and discontinuous in old rats. Age-induced down-regulation of mRNA expression and decreased expressions of zonula occludens and occludin proteins were observed in the ileum [47]. Mabbott [48] stated that the intestinal barrier becomes leaky with age, developing the so-called 'leaky gut'. Increased tight junction permeability leads to increased microbial translocation into mucosal tissue and the blood stream, resulting in increased systemic inflammatory cytokine production [49]. Zhang et al. [50] stated that disruption of tight junction complexes is associated with a variety of diseases including genital and gastric cancers, inflammatory bowel disease, and HIV infection. In addition, flavonoids are involved in the quercetin-mediated enhancement of the intestinal tight junction barrier function. Flavonoids are supposed to mediate cellular biological effects through the interaction with intercellular signaling molecules, such as protein kinases, rather than through their antioxidant properties [51].

In conclusion, we confirmed the occurrence of the age-related histological, ultrastructural and functional changes in rat jejunal mucosa. These alterations may be responsible for increased frequency of gastrointestinal disorders such as irritable bowel syndrome and constipation in the elderly. We suggest that these changes could be ameliorated by the green tea powerful antioxidative and apoptosis-regulating properties.

\section{Conflict of interest}

\section{None declared.}

\section{References}

1. Saffrey MJ. Aging of the mammalian gastrointestinal tract: a complex organ system. Age (Dordr). 2014; 36(3): 9603, doi: 10.1007/s11357-013-9603-2, indexed in Pubmed: 24352567. 
2. Wang Li, Li J, Li Q, et al. Morphological changes of cell proliferation and apoptosis in rat jejunal mucosa at different ages. World J Gastroenterol. 2003; 9(9): 2060-2064, indexed in Pubmed: 12970906.

3. Williams JM, Duckworth CA, Burkitt MD, et al. Epithelial cell shedding and barrier function: a matter of life and death at the small intestinal villus tip. Vet Pathol. 2015; 52(3): 445-455, doi: 10.1177/0300985814559404, indexed in Pubmed: 25428410 .

4. Wong WM, Wright NA. Cell proliferation in gastrointestinal mucosa. J Clin Pathol. 1999; 52(5): 321-333, indexed in Pubmed: 10560350.

5. Firth M, Prather CM. Gastrointestinal motility problems in the elderly patient. Gastroenterology. 2002; 122(6): 1688-1700 , indexed in Pubmed: 12016432.

6. Drozdowski L, Thomson A. Aging and the intestine. World J Gastroenterol. 2006; 12(47): 7578-7584, doi: 10.3748/wjg. v12.i47.7578.

7. Al-Qudah M. Histological effects of aging on male albino rats' duodenum. World J Med Sci. 2014; 10(2): 174-178, doi: 10.5829/idosi.wjms.2014.10.2.82220.

8. Barratt SM, Leeds JS, Robinson K, et al. Reflux and irritable bowel syndrome are negative predictors of quality of life in coeliac disease and inflammatory bowel disease. Eur J Gastroenterol Hepatol. 2011; 23(2): 159-165, doi: 10.1097/ MEG.0b013e328342a547, indexed in Pubmed: 21178777.

9. Tosato M, Zamboni V, Ferrini A, et al. The aging process and potential interventions to extend life expectancy. Clin Interv Aging. 2007; 2(3): 401-412, indexed in Pubmed: 18044191.

10. Møller P, Løhr M, Folkmann JK, et al. Aging and oxidatively damaged nuclear DNA in animal organs. Free Radic Biol Med. 2010; 48(10): 1275-1285, doi: 10.1016/j.freeradbiomed.2010.02.003, indexed in Pubmed: 20149865.

11. Kusano C, Ferrari B. Total antioxidant capacity: a biomarker in biomedical and nutritional studies. J Cell Mol Biol. 2008; 7: $1-15$.

12. Smith PD, Smythies LE, Shen R, et al. Intestinal macrophages and response to microbial encroachment. Mucosal Immunol. 2011; 4(1): 31-42, doi: 10.1038/mi.2010.66, indexed in Pubmed: 20962772.

13. Singh BN, Shankar S, Srivastava RK. Green tea catechin, epigallocatechin-3-gallate (EGCG): mechanisms, perspectives and clinical applications. Biochem Pharmacol. 2011; 82(12): 1807-1821, doi: 10.1016/j.bcp.2011.07.093, indexed in Pubmed: 21827739.

14. Ferrari CKB. Functional foods, herbs and nutraceuticals: towards biochemical mechanisms of healthy aging. Biogerontology. 2004; 5(5): 275-289, doi: 10.1007/s10522-004-2566-z, indexed in Pubmed: 15547316.

15. Chen L, Mo H, Zhao L, et al. Therapeutic properties of green tea against environmental insults. J Nutr Biochem. 2017; 40: 1-13, doi: 10.1016/j.jnutbio.2016.05.005, indexed in Pubmed: 27723473.

16. Yin Z, Henry EC, Gasiewicz TA. Epigallocatechin-3-gallate is a novel Hsp90 inhibitor. Biochemistry. 2009; 48(2): 336-345, doi: 10.1021/bi801637q, indexed in Pubmed: 19113837.

17. Murase T, Haramizu S, Ota N, et al. Tea catechin ingestion combined with habitual exercise suppresses the aging-associated decline in physical performance in senescence-accelerated mice. Am J Physiol Regul Integr Comp Physiol. 2008; 295(1): R281-R289, doi: 10.1152/ajpregu.00880.2007, indexed in Pubmed: 18480242.

18. Gad SB, Zaghloul DM. Beneficial effects of green tea extract on liver and kidney functions, ultrastructure, lipid profile and hematological parameters in aged male rats. Global Vet. 2013; 11(2): 191-205.

19. Kara A, Unal D, Simsek N, et al. Ultra-structural changes and apoptotic activity in cerebellum of post-menopausal-diabetic rats: a histochemical and ultra-structural study. Gynecol Endocrinol. 2014; 30(3): 226-231, doi: 10.3109/09513590.2013. 864270, indexed in Pubmed: 24397360.

20. Bancroft J, Layton C. The Hematoxylin and Eosin. In: Suvarna SK, Layton C, Bancroft JD. ed. Theory and Practice of Histological Techniques. 7th ed. Churchill Livingstone of El Sevier, Philadelphia 2013: 172-214.

21. Bancroft J, Gamble A. Theory and Practice of Histological Techniques. 6th edition. Churchill Livingstone, New York, London 2008: 225-249.

22. Karaca T, Simşek N, Uslu S, et al. The effect of royal jelly on $\mathrm{CD} 3(+), \mathrm{CD} 5(+), \mathrm{CD} 45(+)$ T-cell and CD68(+) cell distribution in the colon of rats with acetic acid-induced colitis. Allergol Immunopathol (Madr). 2012; 40(6): 357-361, doi: 10.1016/j.aller.2011.09.004, indexed in Pubmed: 22115572.

23. Hayat MA. Principles and techniques of electron microscopy: biological applications. 4th ed. Cambridge University Press, Cambridge, United Kingdom 2000: 4-85.

24. Giblot Ducray HA, Globa L, Pustovyy O, et al. Mitigation of heat stress-related complications by a yeast fermentate product. J Therm Biol. 2016; 60: 26-32, doi: 10.1016/j.jtherbio.2016.06.002, indexed in Pubmed: 27503713.

25. Foligne B, Sénégas-Balas F, Antoine JM, et al. Trophic status of the small intestine in young and aged rats: modulation by a yogurt-supplemented diet. Dig Dis Sci. 2004; 49(7-8): 1291-1301, indexed in Pubmed: 15387360.

26. Baum B, Meneses F, Kleinschmidt S, et al. Age-related histomorphologic changes in the canine gastrointestinal tract: a histologic and immunohistologic study. World J Gastroenterol. 2007; 13(1): 152-157, indexed in Pubmed: 17206763.

27. Martin K, Kirkwood TB, Potten CS. Age changes in stem cells of murine small intestinal crypts. Exp Cell Res. 1998; 241(2): 316-323, doi: 10.1006/excr.1998.4001, indexed in Pubmed: 9637773.

28. Holt PR, Pascal RR, Kotler DP. Effect of aging upon small intestinal structure in the Fischer rat. J Gerontol. 1984; 39(6): 642-647, indexed in Pubmed: 6491177.

29. Thomson ABR. Small intestinal disorders in the elderly. Best Pract Res Clin Gastroenterol. 2009; 23(6): 861-874, doi: 10.1016/j.bpg.2009.10.009, indexed in Pubmed: 19942164.

30. Gessner DK, Bonarius M, Most E, et al. Effects of dietary polyphenol-rich plant products from grape or hop on pro-inflammatory gene expression in the intestine, nutrient digestibility and faecal microbiota of weaned pigs. BMC Vet Res. 2014; 10(4): 196-284, doi: 10.1186/s12917-014-0196-5, indexed in Pubmed: 25323005.

31. Frejnagel S, Wroblewska M. Comparative effect of green tea, chokeberry and honeysuckle polyphenols on nutrients and mineral absorption and digestibility in rats. Ann Nutr Metab. 2010; 56(3): 163-169, doi: 10.1159/000278747, indexed in Pubmed: 20150725.

32. Karaca T, Uslu S, Yörük M. Effects of green tea and ginseng on villus length and crypt. Depth and on the distribution of mast and goblet cells in the small intestine of rats with streptozotocin (STZ)-induced diabetes. Philipp J Vet Med. 2011; 48(2): 86-94.

33. Kang JM, Kim N, Kim JH, et al. Effect of aging on gastric mucosal defense mechanisms: ROS, apoptosis, angiogenesis, and sensory neurons. Am J Physiol Gastrointest Liver Physiol. 
2010; 299(5): G1147-G1153, doi: 10.1152/ajpgi.00218.2010, indexed in Pubmed: 20724528.

34. Newton JL. Changes in upper gastrointestinal physiology with age. Mech Ageing Dev. 2004; 125(12): 867-870, doi: 10.1016/j. mad.2004.05.007, indexed in Pubmed: 15563932.

35. Rutter K, Sell DR, Fraser N, et al. Green tea extract suppresses the age-related increase in collagen crosslinking and fluorescent products in C57BL/6 mice. Int J Vitam Nutr Res. 2003; 73(6): 453-460, doi: 10.1024/0300-9831.73.6.453, indexed in Pubmed: 14743550.

36. Holt PR, Yeh Ky. Small intestinal crypt cell proliferation rates are increased in senescent rats. J Gerontol. 1989; 44(1): B9-B14, doi: 10.1093/geronj/44.1.b9.

37. Xiao ZQ, Moragoda L, Jaszewski R, et al. Aging is associated with increased proliferation and decreased apoptosis in the colonic mucosa. Mech Ageing Dev. 2001; 122(15): 1849-1864, indexed in Pubmed: 11557285.

38. Hsu S, Lewis J, Singh B, et al. Green tea polyphenol targets the mitochondria in tumor cells inducing caspase 3-dependent apoptosis. Anticancer Res. 2003; 23(2B): 1533-1539, indexed in Pubmed: 12820420.

39. Mikkelsen HB, Rumessen JJ. Characterization of macrophage-like cells in the external layers of human small and large intestine. Cell Tissue Res. 1992; 270(2): 273-279, indexed in Pubmed: 1451172.

40. Kleinschmidt S, Meneses F, Nolte I, et al. Distribution of mast cell subtypes and immune cell populations in canine intestines: evidence for age-related decline in $\mathrm{T}$ cells and macrophages and increase of IgA-positive plasma cells. Res Vet Sci. 2008; 84(1): 41-48, doi: 10.1016/j.rvsc.2007.03.009, indexed in Pubmed: 17521688.

41. Jang I, Jung K, Cho J. Influence of age on duodenal brush border membrane and specific activities of brush border membrane enzymes in Wistar rats. Exp Anim. 2000; 49(4): 281-287, indexed in Pubmed: 11109554.

42. Skrzydlewska E, Ostrowska J, Farbiszewski R, et al. Protective effect of green tea against lipid peroxidation in the rat liver, blood serum and the brain. Phytomedicine. 2002; 9(3): 232-238, doi: 10.1078/0944-7113-00119, indexed in Pubmed: 12046864 .
43. Yu BP. Membrane alteration as a basis of aging and the protective effects of calorie restriction. Mech Ageing Dev. 2005; 126(9): 1003-1010, doi: 10.1016/j.mad.2005.03.020, indexed in Pubmed: 15893361.

44. Łuczaj W, Zapora E, Skrzydlewska E. Influence of green tea on erythrocytes antioxidant status of different age rats intoxicated with ethanol. Phytother Res. 2010; 24(3): 424-428, doi: 10.1002/ptr.2986, indexed in Pubmed: 19777505

45. El-Beshbishy H. Hepatoprotective effect of green tea (Camellia sinensis) extract against tamoxifen-induced liver injury in rats. BMB Reports. 2005; 38(5): 563-570, doi: 10.5483/ bmbrep.2005.38.5.563.

46. Yang CS, Sang S, Lambert JD, et al. Possible mechanisms of the cancer-preventive activities of green tea. Mol Nutr Food Res. 2006; 50(2): 170-175, doi: 10.1002/mnfr.200500105, indexed in Pubmed: 16425280.

47. Ren $\mathrm{Wy}, \mathrm{Wu} \mathrm{Kf}, \mathrm{Li} \mathrm{Xi}$, et al. Age-related changes in small intestinal mucosa epithelium architecture and epithelial tight junction in rat models. Aging Clin Exp Res. 2014; 26(2): 183-191, doi: 10.1007/s40520-013-0148-0, indexed in Pubmed: 24243034.

48. Mabbott NA. A breakdown in communication? Understanding the effects of aging on the human small intestine epithelium. Clin Sci (Lond). 2015; 129(7): 529-531, doi: 10.1042/ CS20150364, indexed in Pubmed: 26186738.

49. Tran L, Greenwood-Van Meerveld B. Age-associated remodeling of the intestinal epithelial barrier. J Gerontol A Biol Sci Med Sci. 2013; 68(9): 1045-1056, doi: 10.1093/gerona/glt106, indexed in Pubmed: 23873964.

50. Zhang JB, Du XG, Zhang H, et al. Breakdown of the gut barrier in patients with multiple organ dysfunction syndrome is attenuated by continuous blood purification: effects on tight junction structural proteins. Int J Artif Organs. 2010; 33(1): 5-14, indexed in Pubmed: 20127656.

51. Suzuki T, Hara H. Role of flavonoids in intestinal tight junction regulation. J Nutr Biochem. 2011; 22(5): 401-408, doi: 10.1016/j.jnutbio.2010.08.001, indexed in Pubmed: 21167699. 